\title{
Simulation of blowing snow over the Antarctic ice sheet
}

\author{
Hubert Gallée* \\ Institut d'Astronomie et de Géophysique G. Lemaître, Université Catholique de Louvain, B-1348 Louvain-la-Neuve, Belgium
}

\begin{abstract}
A preliminary simulation of blowing snow over the Antarctic continent made with a mesoscale atmospheric model is presented. Sensitivity experiments show that the increase of surface friction arising in conjunction with blowing snow has a relatively more important impact on the dynamics of strong katabatic winds than previously supposed. Sublimation in blowing snow over the Antarctic continent also contributes to the global sea-level budget. It is found that this contribution is of the same order of magnitude as the estimated present sea-level rise.
\end{abstract}

\section{INTRODUGTION}

The aim of this paper is to obtain a first-order estimate of the impact of blowing snow on Antarctic katabatic winds. This will be done using a mesoscale atmospheric model developed to study atmospheric circulation in polar regions (Gallée, 1995).

Katabatic wind is the dominating atmospheric circulation near the surface of the Antarctic ice sheet. Its main forcing mechanism results from the formation of cold dense air by radiation cooling over the sloping surface of the ice sheet. This air flows down the slopes and may reach a stormy character in the coastal areas (Parish, 1988).

Katabatic winds are responsible for export of cold continental air over the surrounding ocean and play a significant role in the climatic system of the Southern Hemisphere (e.g. Simmonds and Law, 1995).

In a previous study, Kodama and others (1985) discussed the potential influence of blowing snow on the dynamics of Antarctic katabatic winds. They indentified some processes which are responsible for changes in the strength of the circulation. They noted that the presence of blowing snow particles in the airstream caused an increase in the fluid density, thus increasing the katabatic force. Furthermore, the sublimation of snow absorbs heat and is responsible for an additional cooling and an additional increase in air density. These two processes are referred to below as an increase in air density. Kodama and others (1985) also mentioned that the transfer of kinetic energy from the air near the surface to blowing-snow particles slows down the katabatic airstream but they argued that such a process had a negligible influence. This process is referred to below as an increase of surface friction. Later, Gosink (1989) used a density-current model to study the first two processes and found that they played a somewhat minor role for wind velocities below about $28 \mathrm{~m} \mathrm{~s}^{-1}$.

The impact of the above-mentioned processes on the

\footnotetext{
* This paper was partly written at the Centre d'Études de la Neige, Météo-France/CNRM, 38406 Saint-Martin-d'Hères Cedex, France.
}

simulation of Antarctic katabatic winds is the subject of the present paper. To carry out the study, a crude representation of blowing snow was included in the mesoscale atmospheric model MAR (Modèle Atmosphérique Régional). The relative influence of air-density increase and surface-friction increase was assessed by undertaking experiments in which these processes were either switched on or off. These simulations were then analysed using the factor-separation method developed by Stein and Alpert (1993).

\section{MODEL DESGRIPTION}

The model MAR has been fully described by Gallée and Schayes (1994) and Gallée (1995). A brief description is given here. MAR is a hydrostatic primitive-equation model in which the vertical coordinate is the normalized pressure $\sigma=p-p_{\mathrm{t}} / p_{\mathrm{s}}-p_{\mathrm{t}}\left(p, p_{\mathrm{t}}=\right.$ constant and $p_{\mathrm{s}}$ is the pressure, the model top pressure and the surface pressure, respectively). The full continuity equation is also taken into account.

The vertical sub-grid scale fluxes are treated using the $E-\epsilon$ turbulence model (Duynkerke, 1988), allowing representation of the turbulent mixing length as a function of the local flow characteristics. This is important, because of the complex structure of the katabatic layer (Pettre and André, 1991; Gallée and Schayes, 1992). To represent the vertical sub-grid scale fluxes in the surface layer, the formulation of Duynkerke (1991), developed also to take into account very stable conditions, is used.

The hydrological cycle also includes a cloud microphysical model, with conservation equations for cloud droplet, rain drop, cloud ice crystal and snowflake concentrations. The representation of the cloud microphysical processes is essentially based on the Kessler (1969) parameterization. In particular, the sublimation of snowflakes is a function of the relative humidity of the air.

Detailed solar- and infrared-radiation schemes are used. The solar-radiation scheme is that of Tricot and Berger (1988) modified by Gallée and others (1991). The longwaveradiation scheme follows a wide-band formulation of the radiative-transfer equation (Morcrette, 1984) and was designed for use in general circulation models (GCMs). 
Cloud properties are also taken into account in the solarand infrared-radiation scheme by computing the liquidwater path in each model layer from the hydrometeor concentration.

This model has recently been coupled to a physically based model of the snowpack (Gallée and Duynkerke, 1997) and to a polynya model (Gallée, 1997).

Fluid-density increase due to the presence of hydrometeors and in particular of blowing-snow particles is taken into account in the model by modifying the representation of the virtual temperature and the hydrostatic equation, in a manner comparable to that of Beniston (1980):

$$
\begin{aligned}
T_{\mathrm{v}} & =T\left(1+0.608\left(q_{\mathrm{v}}-1.64\left(q_{\mathrm{i}}+q_{\mathrm{s}}+q_{\mathrm{w}}+q_{\mathrm{r}}\right)\right)\right) \\
\frac{\partial \phi}{\partial\left(\frac{T}{\theta}\right)} & =-C_{\mathrm{p}} \theta\left(1+0.85\left(q_{\mathrm{v}}-1.64\left(q_{\mathrm{i}}+q_{\mathrm{s}}+q_{\mathrm{w}}+q_{\mathrm{r}}\right)\right)\right)
\end{aligned}
$$

where $T_{\mathrm{v}}$ is the virtual temperature, $T$ is the temperature, $\theta$ is the potential temperature, $\phi$ is the geopotential, and $q_{\mathrm{v}}, q_{\mathrm{i}}$, $q_{\mathrm{s}}, q_{\mathrm{w}}$ and $q_{\mathrm{r}}$ are the concentration of water vapor, ice crystals, snowflakes, cloud droplets and rain, respectively.

The increase of surface friction due to blowing snow is parameterized according to Chamberlain (1983) and consists of an increase in the surface-roughness length $z_{0}$ in the case of blowing snow:

$$
z_{0}=0.016 \frac{u_{*}^{2}}{g}
$$

where $u_{*}$ is the friction velocity and $g$ is gravity. A threshold $u_{* t}=0.4 \mathrm{~m} \mathrm{~s}^{-1}$ is chosen under which blowing snow is not allowed to occur. It corresponds to snow having a wind-hardened surface, a commonly observed situation over Antarctica.

The concentration of blowing-snow particles $2 \mathrm{~m}$ above the surface is parameterized according to Budd and others (1966). It is used as the lower boundary condition for snowflake concentrations. The vertical turbulent fluxes of blowing snow are computed by using the same diffusion coefficients as for momentum.

\section{RESULTS}

The impact of blowing snow on the dynamics of Antarctic katabatic winds is analysed in this paper by using the factor-separation method developed by Stein and Alpert (1993). Two factors are considered: (i) the air-density

Table 1. Simulations of Antarctic katabatic wind. Sensitivity

\begin{tabular}{|c|c|c|c|c|c|}
\hline \multirow[t]{4}{*}{$E X P$} & \multicolumn{2}{|c|}{ Factors } & \multicolumn{3}{|c|}{ Model response } \\
\hline & \multirow[t]{3}{*}{$\begin{array}{c}z_{0} \\
\text { increase }\end{array}$} & \multirow[t]{3}{*}{$\begin{array}{c}\text { Air density } \\
\text { increase }\end{array}$} & \multicolumn{2}{|c|}{$\begin{array}{l}\text { Wind speed } \\
\text { speed }\end{array}$} & \multirow{2}{*}{$\begin{array}{l}\text { Sublimation } \\
\text { increase } \\
\text { (continental } \\
\text { average) }\end{array}$} \\
\hline & & & Max. & $r m s$ & \\
\hline & & & $\mathrm{ms}^{-1}$ & $\mathrm{~ms}^{-1}$ & $\mathrm{mmd}^{-1}$ w.e. \\
\hline 00 & OFF & OFF & 13.67 & 4.189 & 0.000 \\
\hline 01 & OFF & $\mathrm{ON}$ & $13.99(+0.32)$ & $4.352(+0.163)$ & 0.086 \\
\hline 10 & ON & OFF & $12.53(-1.14)$ & $4.176(-0.013)$ & -0.012 \\
\hline 11 & $\mathrm{ON}$ & ON & $12.95(-0.72)$ & $4.333(+0.144)$ & 0.087 \\
\hline
\end{tabular}
to blowing snow. Averges and rms (root mean squares) are performed over the continent only. w.e. refers to water equivalent increase and (ii) the surface-friction increase. The factorseparation method allows us to infer the relative influence of each factor and their synergetic effects by performing several experiments. Four experiments are necessary when two factors are considered: one experiment with none of the two factors activated, two experiments, each with only one of the two factors activated, and one experiment with the two factors activated. The last experiment allows us to infer the synergetic effect of one of the factors on the other. The experiments are summarized in Table 1 . The model domain covers Antarctica, with a horizontal grid size of $40 \mathrm{~km}$. The vertical levels are non-uniformly distributed, with the finest discretization near the surface. The reason is that the main part of the circulation occurs in the low troposphere. Their initial heights above the ocean are 15, 31, 118, 238, 400, 564, 817, 1709, 3801, 7400 and $14230 \mathrm{~m}$. Polar-night conditions are assumed. The ocean is covered with sea ice. The initial vertical temperature profile is based on the climatology of Schwerdtfeger (1984). The initial relative humidity is assumed to be 0.3 . This low value has been chosen in order to avoid the generation of high clouds over the Antarctic continent. Note, however, that a large relative error in the initial relative humidity over the plateau generates a small relative error in the specific humidity in the coastal area. For example, if one chooses an initial relative humidity $R H$ amounting to 0.3 rather than 0.7 , the error in the specific humidity would amount roughly to $0.02 \mathrm{~g} \mathrm{~kg}^{-1}$ if the temperature $T$ equals $220 \mathrm{~K}$ over the plateau. This is a much smaller value than the $0.6 \mathrm{~g} \mathrm{~kg}^{-1}$ corresponding to $T \simeq 250 \mathrm{~K}$ and $R H \simeq 0.95$ in katabatic air streams reaching the coastal area. In other words, the model sensitivity to the initial relative humidity is rather small, since continental air coming from the Antarctic plateau experiences an important adiabatic warming (and consequently an important relative drying effect) when it flows down towards the ice-sheet margin. Finally, it must be noted that the simulation is performed over a sufficiently long time to allow the humidity in the lower troposphere to adjust to surface conditions. For example, $R H \simeq 0.6$ at the South Pole after 3 days of integration.

The model is started at rest. Note that the large-scale atmospheric circulation around Antarctica (e.g. the cyclonic activity) is not included in the simulations, because it may interact with the katabatic-wind circulation and seriously complicate interpretation of the model results.

Let us consider first the wind vector on the first model level ( $15 \mathrm{~m}$ above the surface), after 3 days of integration (Fig. 1), for EXP 11 (blowing-snow processes are switched on). The katabatic-wind system is well simulated by the model: winds are almost downslope, especially in topographic confluence zones near the coast. This is because the Coriolis force is relatively small in that area. The relative importance of the Coriolis force increases inland and easterlies are simulated over the Antarctic plateau. As in the observations, easterlies are also simulated along the Antarctic coast.

In the following, one examines the sensitivity of the wind speed to blowing snow (Table 1). Its rms (root mean square) over the continent exhibits an increase when the air-density increase due to blowing snow is taken into account (compare EXP 01 and 11 with EXP 00 and 10, respectively). The impact of the surface-friction increase seems less important and is responsible for a slight decrease in the rms (cf. EXP 10 and 11 with EXP 00 and 01, respectively).

The impact of blowing snow on the speed of strong kata- 


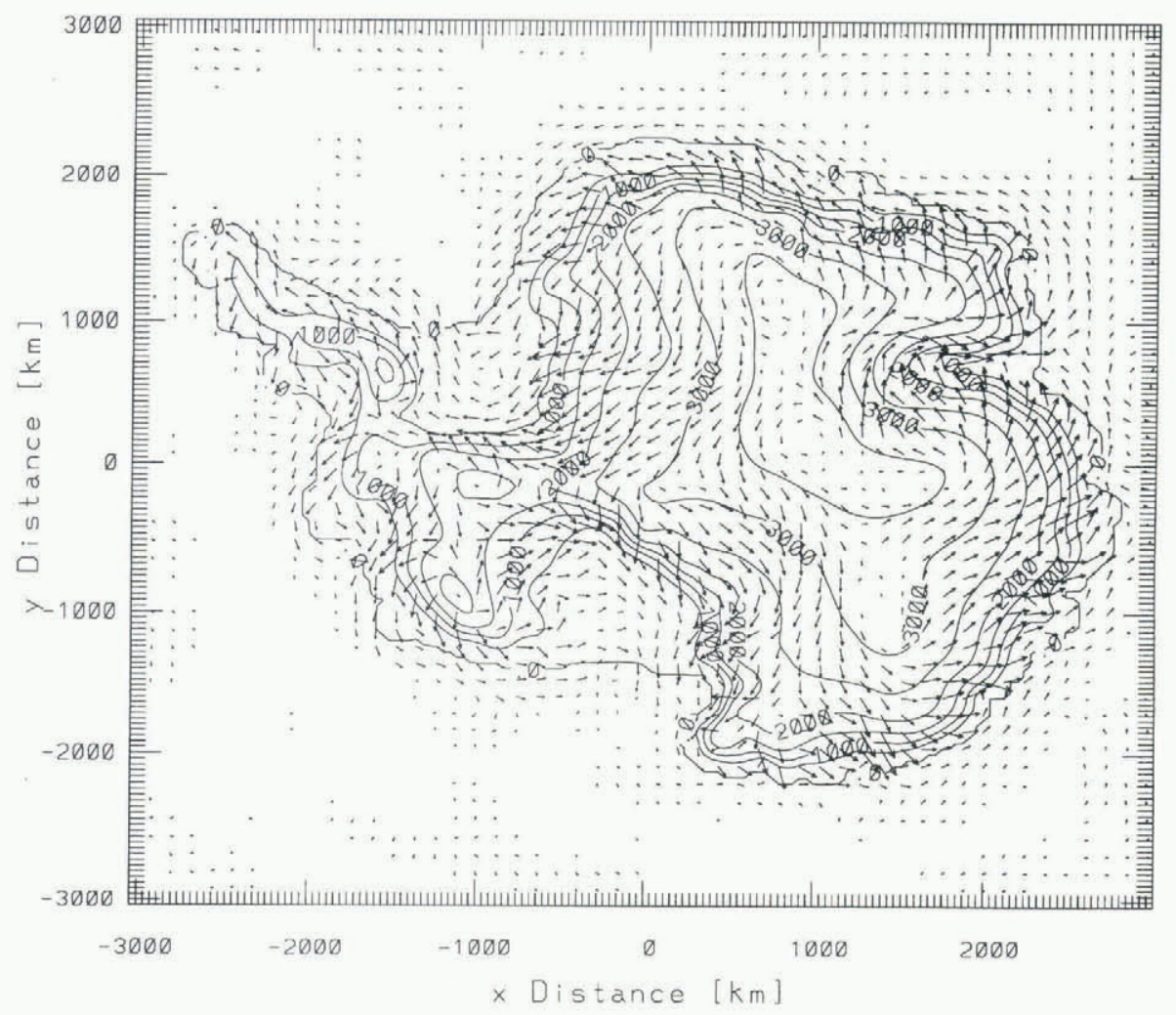

$$
\begin{aligned}
& 15.01380 \\
& \text { MAXIMUM VECTOR }
\end{aligned}
$$

\begin{abstract}
Fig. 1. Simulated katabatic-wind vectors after a 3 day integration for the lowest level of the model ( $15 \mathrm{~m}$ above the surface), for experiment 11 (blowing-snow parameterizations are activated). Ice-sheet elevation contours $(\mathrm{m})$ are also plotted. The contour interval is $500 \mathrm{~m}$. Vectors whose magnitude is less than $1 \mathrm{~m} \mathrm{~s}^{-1}$ are not plotted. Vectors are plotted every four gridpoints. The arrow length at the right bottom corner of the graph represents wind speed amounting to $15 \mathrm{~m} \mathrm{~s}^{-1}$.
\end{abstract}

batic winds may be determined by considering the maximum value of the wind speed. Note that the analysis of this value also allows us to obtain a better insight into the interaction beween katabatic winds and blowing snow, since the impact of blowing snow on atmospheric dynamics is much more marked for the largest wind speeds. It is found that the impact of air-density increase is relatively small $\left(+0.32 \mathrm{~m} \mathrm{~s}^{-1}\right.$, EXP 01). This fact has also been mentioned by Gosink (1989). The largest influence is that of the surfacefriction increase $\left(-1.14 \mathrm{~m} \mathrm{~s}^{-1}\right.$, EXP 10). A weak synergetic effect is also simulated: compared with EXP 00, EXP 11 exhibits a slightly smaller decrease in the maximum wind speed $\left(-0.72 \mathrm{~m} \mathrm{~s}^{-1}\right)$ than the sum of EXP 01 and $10(0.32$ $\left.1.14=-0.82 \mathrm{~m} \mathrm{~s}^{-1}\right)$. Considering EXP 01 and EXP 11, a more efficient vertical turbulent transport of blowing-snow particles and, subsequently, a larger concentration of blowing snow in EXP 11 may be explained by the increase in turbulence in conjunction with the increase of the surface friction.

A comparable synergetic effect may be found when considering the continental average of the daily sublimation rate. It is larger when the increase in both the air density and the surface friction are taken into account $\left(0.087 \mathrm{~mm} \mathrm{~d}^{-1}\right.$ w.e. (water equivalent); EXP 11), than the sum of each effect included separately $(0.086-0.012=$ $0.074 \mathrm{~mm} \mathrm{~d}^{-1}$ w.e.; EXP 01 and 10). Again, this is due to the fact that a larger amount of blowing snow is available for sublimation in EXP 11.

Note that the sublimation rate mentioned in Table 1 is computed as the difference between the current experiment and EXP 00. Furthermore, the model also simulates the generation of clouds and precipitation, and a fraction of water vapour generated by sublimation is recycled as condensation. For this reason, the sublimation rate mentioned in Table 1 could be qualified as a net sublimation rate.

The contribution of sublimation in blowing snow to the surface mass balance of the Antarctic ice sheet seems significant $\left(0.087 \mathrm{~mm} \mathrm{~d}^{-1}\right.$ w.e.). Assuming this value constant in time, the corresponding value for l year is expanded over the world ocean by multiplying it by the ratio of the Antaretic continental surface divided by the world ocean surface. This gives a contribution to the global sea-level annual budget of roughly $1.5 \mathrm{~mm}$. This value may be compared to the present 1-2 $\mathrm{mm} \mathrm{a}^{-1}$ sea-level rise (Weller, 1993).

\section{DISGUSSION}

In order to assess the impact of blowing snow on the dynamics of Antarctic katabatic winds, a crude parameterization of blowing snow has been included in the mesoscale atmospheric model MAR. Concerning the impact of airdensity increase, a general agreement is found with the Gosink (1989) results. A new finding is that the increase in surface friction, in the case of blowing snow, has a relatively larger impact on the dynamics of strong katabatic winds than previously suggested. Note, however, that the present 
study does not include an increase in air stability near the surface due to the presence of blown-snow particles in air. Indeed, the increasing concentration of blowing snow down towards the surface is responsible for a strong increase in the fluid density there (Bintanja, 1998). Such a stabilization is responsible for a reduction in turbulence and a subsequent reduction in the frictional force.

A second point is that the large-scale circulation around Antarctica is not taken into account. The reason for that choice is that the aim of this paper is to compare the relative influence of the main physical processes activated by blowing snow. Nevertheless, the influence of the large-scale forcing may be important, since it may trigger strong katabatic wind events (Murphy and Simmonds, 1993), amplify blowing-snow processes and in turn have a much larger impact on the katabatic-wind circulation than that estimated here.

In the present study, sublimation in blowing snow over the Antarctic continent contributes to the global sea-level budget. This contribution may be viewed as an export of water vapour across the continental boundary, and it is found that it amounts annually to $1.5 \mathrm{~mm}$. Although smaller than the contribution of precipitation, this contribution is relatively significant. Furthermore, it is probably underestimated because the katabatic flow simulated in this study is relatively weak.

Another result of the present simulations is that the transport of blowing-snow particles across the continental boundary is relatively negligible when compared to the transport of water vapour. The relative importance of the former process may increase substantially in rapid katabatic air streams containing blowing snow. Indeed, the katabatic layer in the coastal area is saturated with water vapour in these situations so that sublimation could not increase significantly. By contrast, the concentration of blown-snow particles may still increase in the lowest few metres of the atmosphere. Nevertheless, a possible deepening of the turbulent katabatic layer during strong katabatic events, forced by cyclonic conditions (e.g. Schwerdtfeger, 1984), may also be responsible for an increase in the water-vapour flux across the continental boundary.

In conclusion, a more correct assessment of climatemodel performances over Antarctica would require us to distinguish precipitation and erosion of the snow cover by the wind. Such a refinement justifies further developments of the blowing-snow model.

\section{ACKNOWLEDGEMENTS}

This research is integrated in the Belgian programme Scientific Research on the Antarctic, and was partly conducted during the visit of $\mathrm{H}$. Gallée to CEN. J. C. Branco is acknowledged for drawing the figure at LLN. Thanks are due to N. Materne for typing a part of the manuscript.

\section{REFERENCES}

Beniston, M. 1980. Effets dynamiques et thermodynamiques d'un îlot de chaleur dans un modèle de couche limite à méso-échelle. F. Rech. Almos., 14 (2), 109-128.

Bintanja, R. 1998. The interaction between drifting snow and atmospheric turbulence. Ann. Glaciol., 26. (see paper in this volume).

Budd, W. F., R. J. Dingle and U. Radok. 1966. The Byrd Snow Drift Project: outline and basic results. In Rubin, M. J., ed. Studies in Antarctic meteorology. Washington, DC, American Geophysical Union, 71-134. (Antarctic Research Series 9.)

Chamberlain, A. C. 1983. Roughness length of sea, sand and snow. BoundaryLayer Meteorol., 25(4), 405-409.

Duynkerke, P. G. 1988. Application of the $E-\epsilon$ turbulence closure model to the neutral and stable atmospheric boundary layer. 7. Atmos. Sci., 45(5), 865-880.

Duynkerke, P. G. 1991. Radiation fog: a comparison of model simulations with detailed observations. Mon. Weather Rev., 119 (2), $324-341$.

Gallée, H. 1995. Simulation of the mesocyclonic acitivity in the Ross Sea, Antarctica. Mon. Weather Rev., 123(7), 2051-2069.

Gallée, H. 1997. Air sea interactions over Terra Nova Bay during winter: simulation with a coupled atmosphere-polynya model. 7. Geophys. Res., 102 (DI2), 13,835-13,850.

Gallée, H. and P. G. Duynkerke. 1997. Air-snow interactions and the surface energy and mass balance over the melting zone of west Greenland during the Greenland Ice Margin Experiment. 7. Geophys. Res., 102(D12), 13,813-13,824.

Gallée, H. and G. Schayes. 1992. Dynamical aspects of katabatic winds evolution in the Antarctic coastal zone. Boundary-Layer Meteorol., 59(1-2), $141-161$.

Gallée, H. and G. Schayes. 1994. Development of a three-dimensional meso- $\gamma$ primitive equations model. Katabatic wind simulation in the area of Terra Nova Bay, Antarctica. Mon. Weather Rev., 122 (4), 671-685.

Gallée, H., J. P. van Ypersele, T. Fichefet, C. Tricot and A. Berger. 1991. Simulation of the last glacial cycle by a coupled, sectorially averaged climate-ice sheet model. 1. The climate model. 7. Geophys. Res., 96(D7), $13,139-13,161$.

Gosink, J. P. 1989. The extension of a density current model of katabatic winds to include the effects of blowing snow and sublimation. BoundaryLayer Meteorol., 49(4), 367-394.

Kessler, E. 1969. On the distribution and continuity of water substance in atmospheric circulation. Meteorol. Monogr. 27.

Kodama, Y., G. Wendler and J. Gosink. 1985. The effect of blowing snow on katabatic winds in Antarctica. Ann. Glaciol., 6, 59-62.

Morcrette, J. J. 1984. Sur la paraméterisation du rayonnement dans les modèles de la circulation générale atmosphérique. (Thèse de doctorat d’état, Université des Science et Technologie de Lille, Lille.)

Murphy, B. F. and I. Simmonds. 1993. An analysis of strong wind events in a GCM near Casey in the Antarctic. Mon. Weather Rev., 121 (2), 522-534.

Parish, T. R. 1988. Surface winds over the Antarctic continent: a review. Rev. Geophys., 26(1), 169-180.

Pettré, P. and J. C. André. 1991. Surface pressure change through Loewe's phenomena and katabatic flow jumps: study of two cases in Adélie Land, Antarctica. 7. Atmos. Sci., 48(4), 557-571.

Schwerdtfeger, W. 1984. Weather and climate of the Antarctic. Amsterdam, Elsevier. (Developments in Atmospheric Science 15.)

Simmonds, I. and R. Law. 1995. Associations between Antarctic katabatic flow and the upper level winter vortex. Int. F. Climatol., 15(4), 403-421.

Stein, U. and P. Alpert. 1993. Factor separation in numerical simulations. $f$. Atmos. Sci., 50(14), 2107-2115.

Tricot, C. and A. Berger. 1988. Sensitivity of present-day climate to astronomical forcing. In Wanner, H. and U. Siegenthaler, eds. Long and short term variability of climate. Bern, Springer Verlag, 132-152. (Lecture Notes in Earth Sciences 16.

Weller, G. 1993. The role of the Antarctic in global change; an international plan for a regional research programme. Cambridge, Scientific Committee on Antarctic Research (SCAR). 